\title{
Concrete Fabric New Technology in Concrete Structures
}

\author{
Khalil tabatabaei $^{1 *}$, farhad tabatabaei ${ }^{2}$ \\ ${ }^{I}$ M.Sc. Student in Construction Management, Tabriz Azad University, Faculty of Civil Engineering, Member of \\ Young Researchers Club \\ ${ }^{2}$ Graduate student of Urmia University, Faculty of Civil Engineering
}

*Corresponding Author: Khalil tabatabaei, M.Sc. Student in Construction Management, Tabriz Azad University, Faculty of Civil Engineering, Member of Young Researchers Club

\begin{abstract}
Using fabric formwork, it is possible to cast architecturally interesting, optimised structures that use up to $40 \%$ less concrete than an equivalent strength prismatic section, thereby offering significant embodied energy savings. This paper reports on the latest techniques for the design, optimisation and shape prediction of fabric formed concrete beams before new test results of an innovative anchorage method for both steel and fibre reinforced polymer longitudinal reinforcing bars are presented. Two $2 m$ span beams were tested and the 'helically confined splayed bar' was shown to provide full anchorage in both cases. The two beams both exceeded their design capacity and showed remarkably similar behaviour at the serviceability limit state, with the steel reinforced section going on to display considerable ductility. Potential areas of future development are then highlighted, with the use of woven advanced composite fabrics as participating formwork for both beam and shell elements being of particular interest.
\end{abstract}

Keywords: Anchorage, Concrete Fabric, participating formwork, strength

\section{INTRODUCTION}

Fabric formwork technology has been under development since the early 1900s, with methods stemming mainly from work in offshore and geotechnical engineering. Its use grew in the 1960s, precipitated by the availability of high strength, low cost fabrics that allowed the easy formation of complex shapes ${ }^{1}$. Architectural interest in the possibilities of fabric formwork was begun by Miguel Fisac, whose early work in Madrid culminated in a patented method for the prefabrication of fabric formed wall panels ${ }^{2}$. Subsequent work has been led by Professor West at the University of Manitoba's Centre for Architectural Structures and Technology (C.A.S.T), the world's first research centre dedicated to the promulgation of fabric formwork as both an architectural form and a new construction philosophy.

The ubiquitous use of orthogonal timber or steel moulds as formwork for concrete structures has resulted in a well-established vocabulary of primarily prismatic structural forms. These 'zerodeflection' formwork systems resist considerable hydrostatic pressures and consume significant amounts of material. Moreover, the resulting prismatic sections require more material and have a higher deadweight than an equivalent variable section member

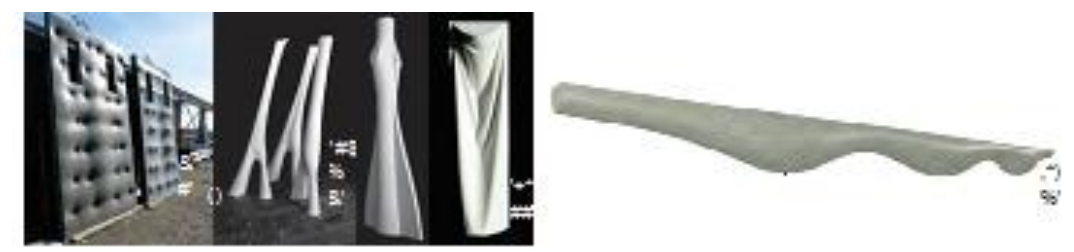

Figure1. Fabric formed concrete structures

Forming concrete in a permeable fabric mould has two fundamental consequences. By allowing air and water to escape from the mould, moderate reductions in water: cement ratio are seen, which in turn bring small increases in compressive strength. More importantly, the external concrete surface is now generally free of voids, reducing the ingress of air and water into the section and improving 
durability. In turn, this can reduce cover requirements for the internal reinforcement and provides a high quality surface finish to the structure.

Whilst architectural interest in this field is growing, the advantages of fabric formwork are yet to be fully realised by the construction industry. This paper presents new test data to illustrate the use of both advanced composites and steel as internal reinforcement in fabric formed structures. An innovative anchorage method, used here in beam tests for the first time, is also assessed before the potential future development of fabric formwork technology is discussed.

\section{RESEARCH SigNIFICANCE}

Concrete has relatively low embodied energy but is used in vast quantities: in 2008 world production of cement was approximately $2.8 \times 10^{9}$ metric tons ${ }^{3}\left(2.8 \times 10^{12} \mathrm{~kg}\right)$ and its manufacture accounted for almost $3 \%$ of global $\mathrm{CO}_{2}$ emissions ${ }^{4}$, suggesting that concrete should be cast in optimised structures. Fabric formwork at last provides a suitable method to achieve these reductions by facilitating the production of variable section members (Figure 1). Concrete volume savings of up to $40 \%{ }^{5,6}$ are feasible and the use of fibre-reinforced polymers as either internal or external reinforcement presents exciting new opportunities for the practical use of fabric formwork.

\section{DESIGN}

Structural design procedures for bending moment shaped beams, as developed at the University of Bath $^{5,6}$, are based on a sectional approach that aims to satisfy the bending and shear requirements of the beam at every point along its length, as summarised in Figure 2. The final shape of the fabric formed beam is determined by a combination of the fabric's material properties and the boundary conditions imposed on it during construction. Accurate shape predictions of the fluid filled fabric are therefore required, from which the construction boundary conditions are determined.

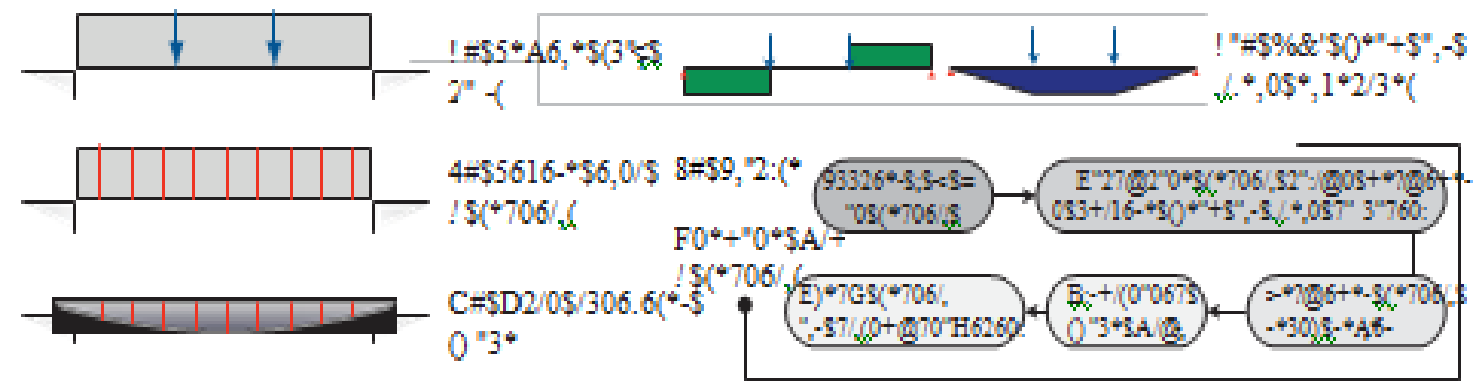

Figure2. Design method for fabric formed structures

\subsection{Form Finding}

Predicting the hydrostatic shape of a fluid filled fabric envelope based on a set of given boundary conditions can be achieved in a number of ways. Schmitz ${ }^{7}$ used an iterative procedure in ADINA to determine the shape of fluid filled wall panels, while Veenendaal ${ }^{8}$ implemented dynamic relaxation to predict the final shape of fabric formed beams. Empirical relationships determined by Bailiss ${ }^{5}$ provide a less rigorous solution to the same problem, but have nevertheless been used successfully ${ }^{6}$, while Foster ${ }^{9}$ used a simple step wise spreadsheet based method to iteratively determine the shape of the hanging fabric membrane (Figure 3). The complete solution, which requires the use of incomplete elliptic integrals, is given separately by Iosilevskii ${ }^{10}$.
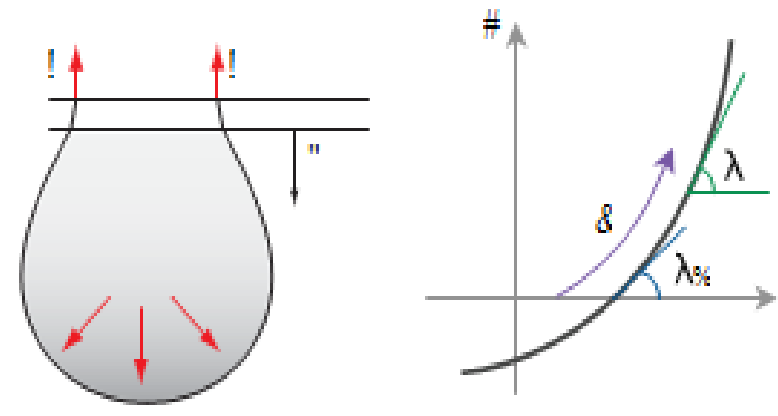

Figure3. Form finding the hydrostatic shape. 


\subsection{Cross Section Design}

For a given loading envelope, the beam must have sufficient capacity in both flexure and shear at every point along its length. Flexural strength calculations are undertaken using the plane section hypothesis, which is widely accepted as an accurate and reliable design method that itself forms the basis of many concrete design codes, including BS EN 1992-1-1 ${ }^{11}$ and ACI 318 ${ }^{12}$. For steel reinforced structures it is first assumed that the longitudinal steel has yielded, from which the effective depth required to resist the applied moment is easily determined (Figure 4). Where fibre reinforced polymer reinforcement is used, an iterative approach must always be taken to ensure that the section is over reinforced and in equilibrium. The effective depth determined for flexure may later be increased to satisfy the requirements for shear force capacity, as discussed below.

Longitudinal reinforcement in fabric formed beams has previously been limited to single steel bars, bent to the desired profile and anchored at their ends by means of a structural weld to an external plate (Figure 5). However, the potential for brittle failures and increased construction complexity when using welded connections means that their use is generally discouraged. In addition, the external plate exposes the internal reinforcement to an increased risk of corrosion. The use of advanced composite reinforcement offers an obvious solution to such concerns, but since these bars cannot be bent or welded an alternative anchorage method is required. Splayed bars, as described below, offer the potential to provide the required anchorage without compromising structural performance.
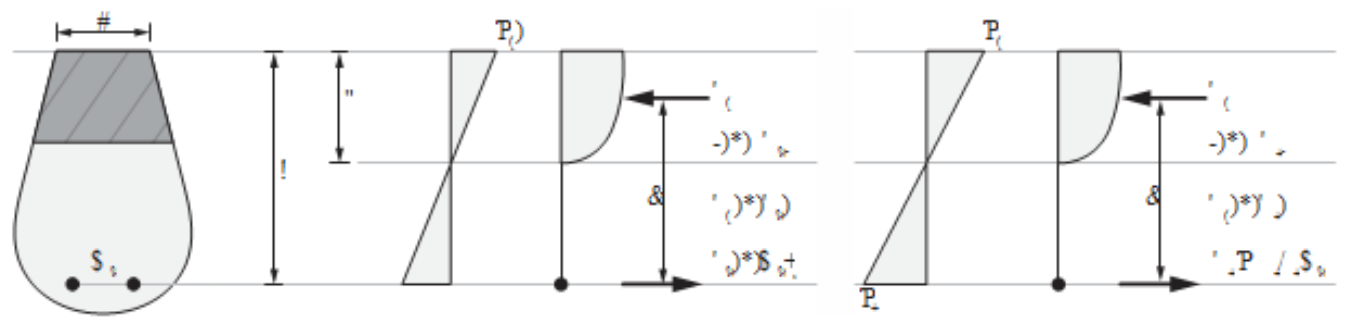

Figure4. Steel (left) and Composite (right) flexural design basis

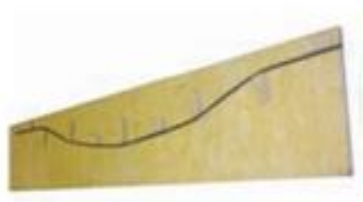

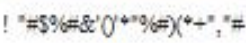

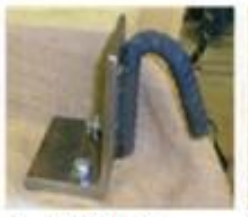

(l) $/ " \$ n=\$ 012-"$

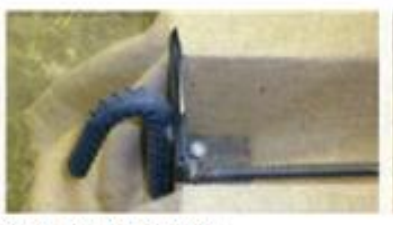

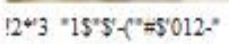

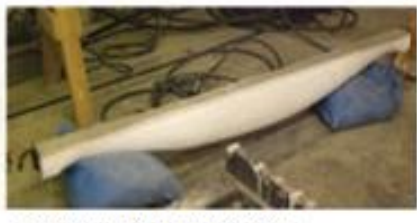

" $2,3 \%-4^{\prime \prime}=5012-{ }^{\prime} 5^{\prime} 6 \% 5 \% 71^{\prime}$

Figure5. Anchorage using welded end plates.

The shear capacity of fabric formed beams is presently assessed using BS 8110-1 ${ }^{13}$. For sections longitudinally reinforced with steel, Eq.(1) is used, while Eq.(2) is used for sections with advanced composite reinforcement. The equations, which were used in the experimental program described later, allow the designer to determine the section dimensions required at each point along the beam to resist shear. However, the shear behaviour of concrete is poorly understood ${ }^{14}$ and the use of empirically derived shear formulae for the analysis of variable section members is of questionable validity. steel ( )( 100As )1/3( 400) 0.25(fcu) $1 / 3$

$V_{\text {capacity }}=b d 0.79 \|(b d\|\| d\|\| 25 \|$

VcapacityFRP $=(b d) 0.79\left(\| \quad 100_{b d} A s\right.$ Esf $|\|1 / 3(|| \quad 400 d)\| \quad 0.25 \|(25 f c u)| \mid 1 / 3$

Where $A_{s}=$ reinforcement area; $f_{c u}=$ concrete cube strength; $b=$ section effective breadth; $d=$ depth to reinforcement; $E_{f}=$ Young's Modulus of FRP; $E_{s}=$ Young's Modulus of Steel.

The two areas of potential design deficiency outlined above are further illustrated by considering the available structural test data. To date, a total of six $2 \mathrm{~m}$ span steel reinforced fabric formed beams have been tested in five point bending at the University of Bath ${ }^{15}$, five of which were found to fail in diagonal tension close to their supports, Figure 6. Whilst such failures are generally undesirable, considerable flexural cracking along the length of the beam was also recorded during loading, indicating near uniform stress in the extreme fibres ${ }^{16}$. Load capacity and deflection response 
predictions were accurate in most cases, suggesting that future design procedures should concentrate on the provision of post-peak ductility to prevent sudden and catastrophic shear failures from occurring.

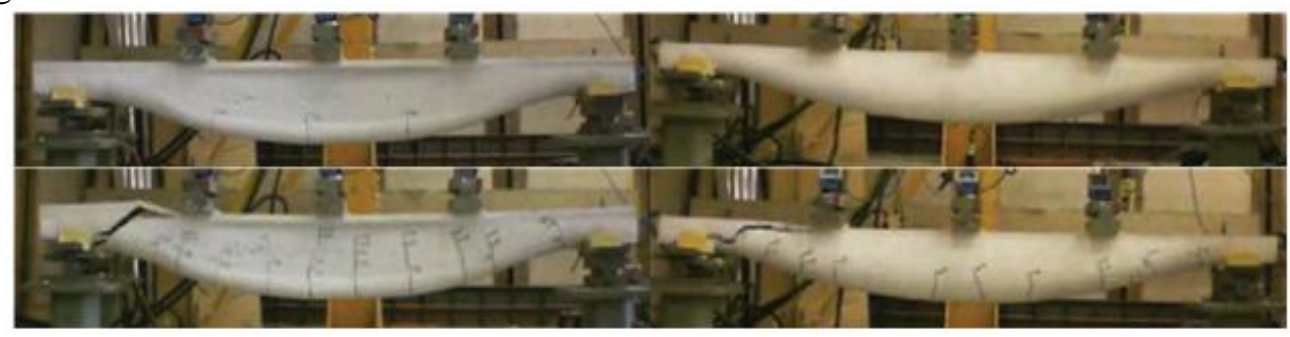

Figure6. Fabric beam tests

\section{Splayed Bars}

An innovative method for the provision of anchorage to longitudinal reinforcement in fabric formed structures where welded connections are not possible is now considered in more detail. The splayed bar utilises wedging action to provide anchorage and has been proven in cube pull out tests ${ }^{17}$, where order of magnitude increases in load and displacement capacity were seen in comparisons between straight and splayed glass fibre reinforced polymer (GFRP) bars. The inclusion of helical reinforcement (Figure 7) to confine the concrete and delay tensile splitting failure was found to provide the greatest increases in capacity. However, such tests place the concrete cube into compression and are therefore unrepresentative of the state of stress around the flexural reinforcement inside an element in bending.
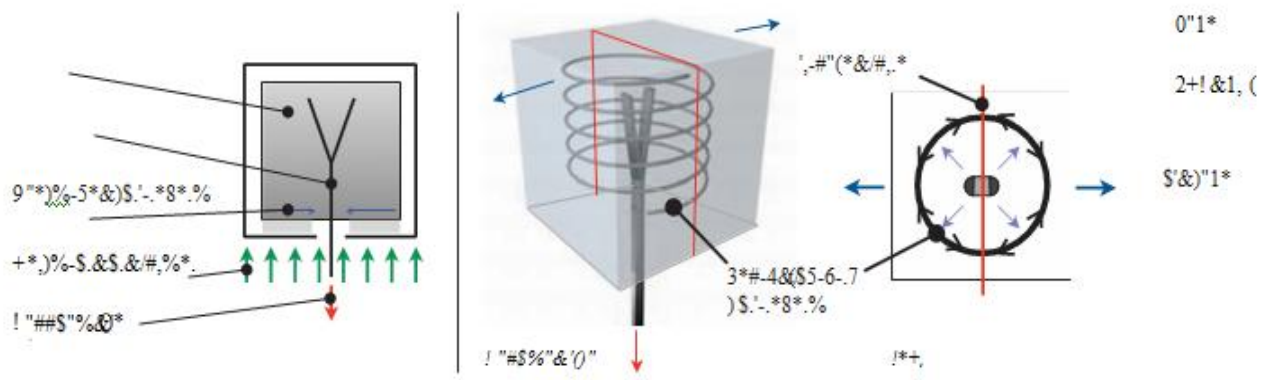

Figure7. Pull out test (l); Helical confinement (r).

\section{Experimental Program}

To fully assess the behaviour of the splayed anchor in both steel and advanced composite reinforced structures, two fabric formed beams were tested. The beams (which were unreinforced in shear) were designed in accordance with the methods described above for the loading envelope shown in Figure 8(1). The beams were designed with a ' $\mathrm{T}$ ' section at their midspan, transitioning to a hydrostatic cross section $500 \mathrm{~mm}$ from the supports. This ensured that a sufficient concrete area was provided in areas of high shear, while also minimising the beam's cross sectional area in those regions dominated by flexural capacity. For initial design, a steel yield stress of $500 \mathrm{MPa}(72 \mathrm{ksi})$, concrete strength of $30 \mathrm{MPa}(4350 \mathrm{psi})$ and carbon fibre reinforced polymer (CFRP) ultimate tensile strength of $2300 \mathrm{MPa}$ (333ksi) and Young's Modulus of $130 \mathrm{GPa}(18,855 \mathrm{ksi})$ was assumed. Using this data, the required beam dimensions were determined at 20 sections along the length of the beam.
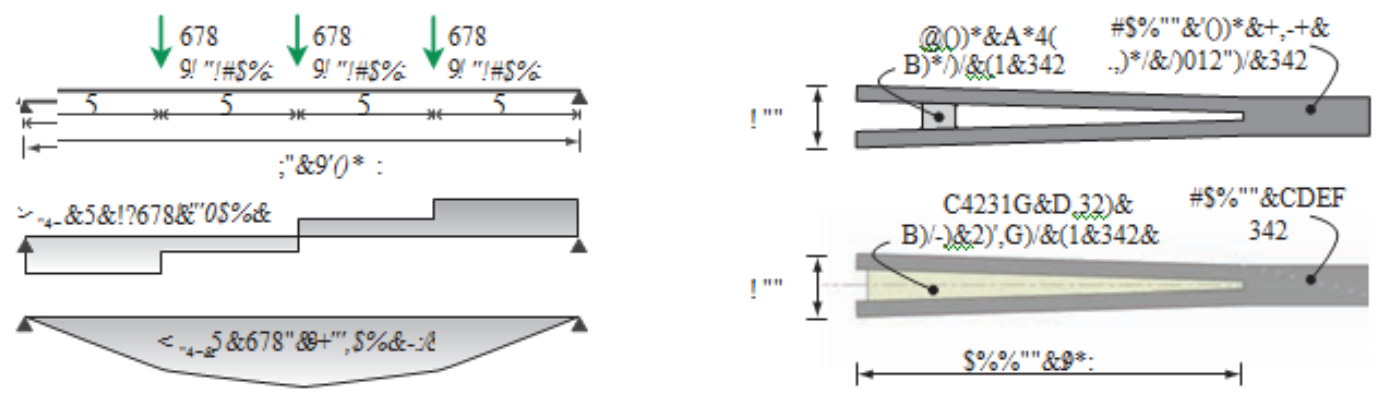

Figure8. Loading envelope for design (l); splay dimensions, steel and FRP bars (r). 
Beam 1 (Figure 9(1)) was longitudinally reinforced with a single $10 \mathrm{~mm}$ diameter high yield steel bar, both ends of which were splayed as shown in Figure 8(r). The bar was confined in the end zone with a helix constructed of $3 \mathrm{~mm}$ diameter high tensile steel wire (outer diameter $30 \mathrm{~mm}$, with a pitch of $10 \mathrm{~mm}$ ). Beam 2 (Figure 9(r)) was longitudinally reinforced with a single $10 \mathrm{~mm}$ diameter CFRP bar, both ends of which were splayed as shown in Figure 8(r) that was confined in the end zone with a helix specially constructed using AFRP rope impregnated with an epoxy resin. Actual material properties for both beams (as measured prior to testing) are provided in Table 1 and salient dimensions of the beams, which vary in both cross section and elevation, are provided in Figure 9.

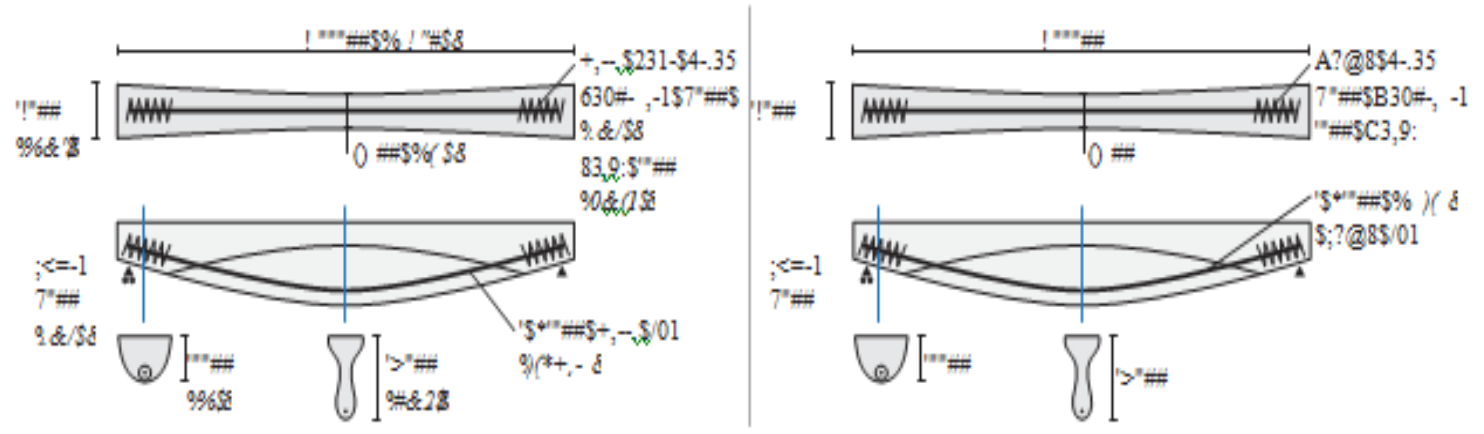

Figure9. Beam $1(l)$; Beam $2(r)$.

Table1. Measured material properties for both tests.

\begin{tabular}{|c|c|c|c|}
\hline $\begin{array}{c}\text { Beam } \\
\# \\
\end{array}$ & Longitudinal reinforcement & Transverse reinforcement & $\begin{array}{c}\text { Concrete cube } \\
\text { strength, } f_{c u}\end{array}$ \\
\hline 1 & $\begin{array}{c}\varnothing 10 \mathrm{~mm}\left(0.39^{\prime \prime}\right) \text { deformed steel, } \\
f_{y}=650 \mathrm{MPa}(94.3 \mathrm{ksi}) ; \mathrm{E}= \\
200 \mathrm{GPa}(29,008 \mathrm{ksi})\end{array}$ & $\begin{array}{c}\text { 30mm diameter, } 10 \mathrm{~mm} \text { pitch helix of } \\
\text { 3mm diameter high tensile steel wire }\left(f_{y}\right. \\
\left.=650 \mathrm{~N} / \mathrm{mm}^{2}\right)\end{array}$ & $42 \mathrm{MPa}(6.1 \mathrm{ksi})$ \\
\hline 2 & $\begin{array}{c}\emptyset 10 \mathrm{~mm} \text { CFRP }, f_{f u}=2300 \mathrm{MPa} \\
(333 k s i) ; \mathrm{E}= \\
130 \mathrm{GPa}(18,855 \mathrm{ksi})\end{array}$ & $\begin{array}{c}\text { 30mm diameter, } 10 \mathrm{~mm} \text { pitch helix of } \\
\text { AFRP Rope }(E=126.5 \mathrm{GPa} \\
\left.(18,710 \mathrm{ksi}), f_{f u}=1.9 \mathrm{GPa}(276 \mathrm{ksi})\right) \\
\text { impregnated with Epoxy resin })\end{array}$ & $41 \mathrm{MPa}(5.9 k s i)$ \\
\hline
\end{tabular}

The beams were constructed in a hanging hessian fabric mould that was fixed in position along two line supports, with the ' $T$ ' section created using curved timber formers, as shown in Figure 10. Construction methods for fabric formed beams are discussed in further detail elsewhere ${ }^{2}$.
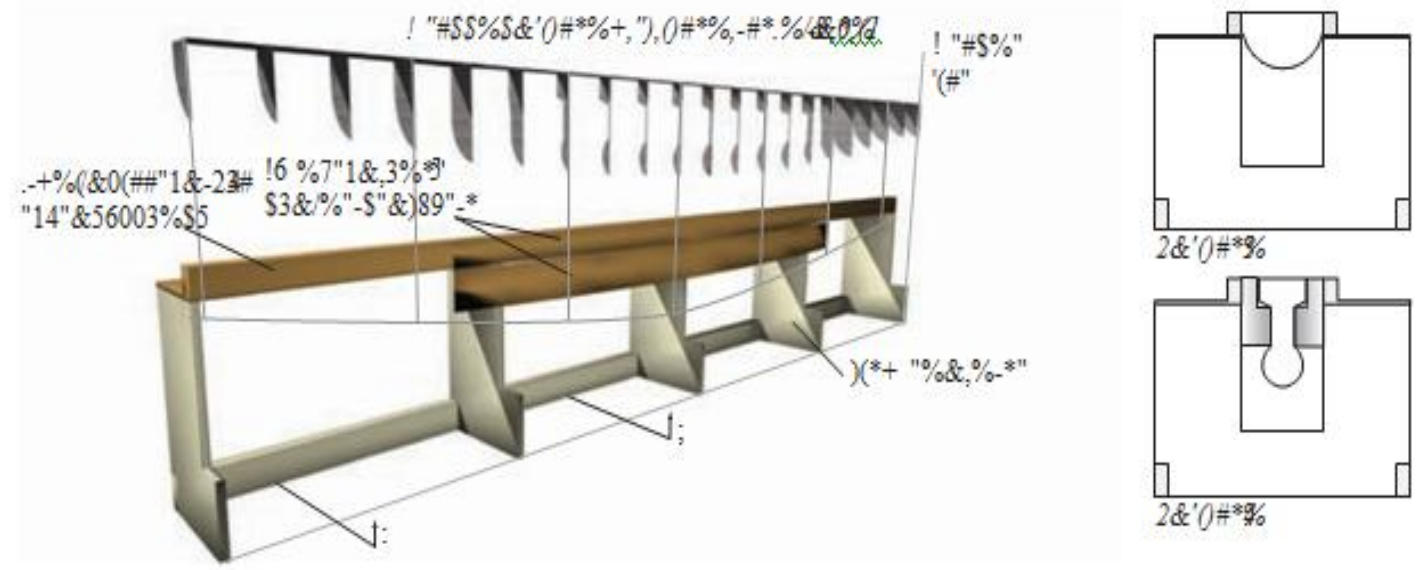

Figure10. Beam construction method.

\subsection{Test Details}

Each beam was loaded through three jacks, positioned a quarter-span apart and hydraulically connected to one hand pump to ensure equal load distribution. A load cell and displacement transducer were connected to the bottom of each jack and strain gauges were placed at four points along the length of each reinforcing bar. A small plug was placed at one end of each reinforcing bar to facilitate the measurement of bar slip during testing. 


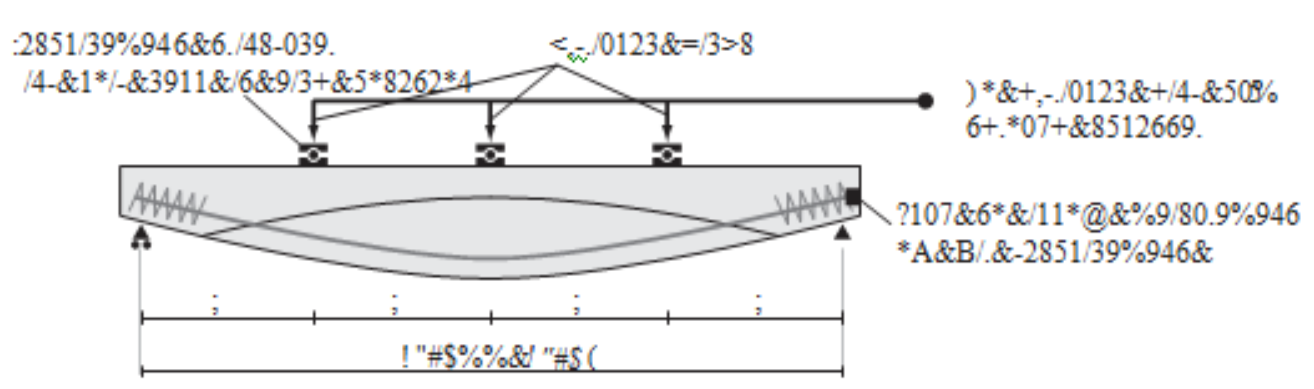

Figure11. Test setup

\subsection{Test Results}

After an approximately linear initial load-displacement response, Beam 1 exhibited considerable ductility before failing at a total load of $26 \mathrm{kN}$ (5.85kips). Flexural cracking, as shown in Figure 12(1), was considerable, and failure occurred due to crushing of the compression zone after the longitudinal steel had yielded. Cracking was well distributed along the length of the beam, indicating a constant stress in the bar, as expected by merit of the design procedure used. Removal of the end plugs on the longitudinal bar after testing revealed that the splayed anchor in Beam 1 had moved by less than $1 \mathrm{~mm}$ when compared to its original position.

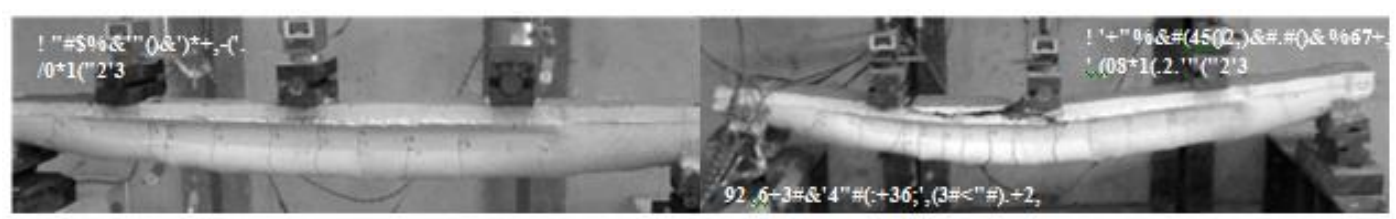

Figure12. Test photographs, Beam 1
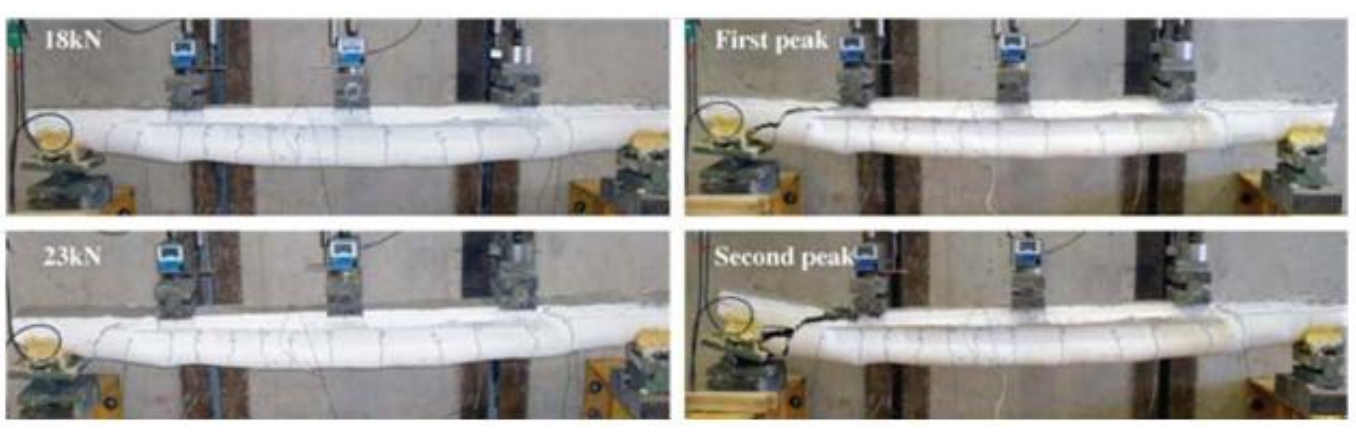

Figure13. Test photographs, Beam 2

Beam 2 (Figure 13) displayed a similar response to Beam 1 in the serviceability condition, yet failed in a more brittle diagonal tension mode close to the supports after displaying some flexural cracking in the main span. A wide inclined crack opened up close to the roller support at a total load of approximately $27 \mathrm{kN}$ (First Peak, Figure 13). Load was then reapplied and the beam reached a second peak of $25 \mathrm{kN}$ before complete failure of the CFRP bar occurred. Analysis of the beam revealed that the splayed anchor had slipped by less than $1 \mathrm{~mm}$ and that failure occurred after the CFRP bar ruptured at the position of the inclined crack, as shown by the photographs in Figure 14. The load displacement responses of both beam tests are shown in Figure 15, where a reduction in stiffness is seen in Beam 2 under re-loading.

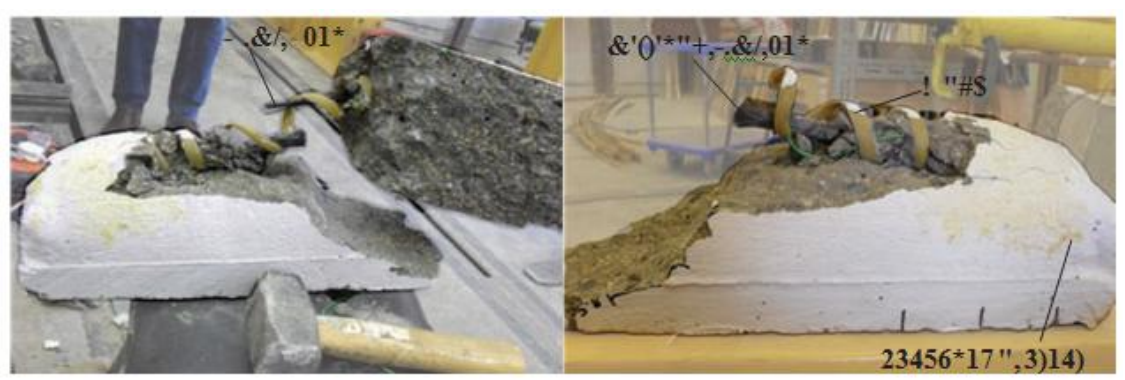

Figure14. CFRP bar rupture 


\subsection{Analysis}

Figure 15 illustrates that the serviceability behaviour of both beams was very similar, as was their peak load capacity. Beam 1 displayed an ideal failure mode, moving from almost linear elastic to perfect plastic behaviour after the section cracked. Although the ultimate load $(26 \mathrm{kN})$ was higher than the design load $(15 \mathrm{kN})$, this can in part be attributed to an increased steel yield stress in the real section over that assumed for design, along with a slightly altered beam section in testing due to variability in construction. A total of $58 \mathrm{~mm}$ deflection at a constant load of $23 \mathrm{kN}$ was recorded, and the splayed anchor was successfully used to provide anchorage to the steel bar.

The behaviour of Beam 2 was less ideal, since the section was designed to fail by concrete crushing at the midspan before the CFRP bar was able to rupture. At the initial peak, the average bar stress at a position $500 \mathrm{~mm}$ from the support was far less than the bar's ultimate tensile capacity, as shown in Eqs.(3-4). This suggests that failure of the CFRP occurred due to a high local strain across the crack, which in turn confirms that a proper assessment of the bond between the fibre reinforced polymer bar and its surrounding concrete is of great importance.

$$
\begin{aligned}
& F_{f}={ }^{M}=\frac{13,500 \times 500=48 \mathrm{kN}(10.8 \mathrm{kips}) \mathrm{Eq} .(3) z}{F^{f}} \quad{ }^{48200} 2 \\
& \sigma_{f}==\overline{61} 8 \overline{\mathrm{N} / \mathrm{mm}}(89.6 \mathrm{ksi}) \mathrm{Eq} .(4) A_{f} \quad 78
\end{aligned}
$$

In a hypothetical, fully bonded section the strain in the longitudinal reinforcement and its surrounding concrete are the same. At the onset of cracking, local strains in the bar increase rapidly and since fibre reinforced polymer bars are unable to yield and maintain compatibility by stretching plastically, they will fail as soon as a limiting strain capacity is reached ${ }^{18}$ (Figure 16). Conversely, in a section with zero bond between the bar and concrete, strains in the reinforcement are low since it is able to move relative to the concrete and whilst failure due to high local strains may now be prevented, lower strains in the reinforcement limit the moment capacity of the section. It is therefore important that a partial bond is achieved to obtain the best of both situations. In tests on prestressed aramid fibre reinforced beams, Lees and Burgoyne ${ }^{18}$ showed that such a partial bond was able to provide both high moment and high rotation capacity.

Although the failure mode of Beam 2 was not ideal, the test showed that the helically confined splayed bar is an effective means by which full anchorage can be provided when advanced composite reinforcement is used, allowing the bar to develop its full strength without slipping at the end zones. The provision of helical confinement is considered to be important for both cases, potentially preventing premature tensile splitting of the end zone as the force on the splayed bar increases under loading, although this improvement has not been quantified. Whitehead ${ }^{19}$ further showed that the provision of helical confinement increases the shear capacity of advanced composite reinforced beams, although this effect was not considered during the design process.

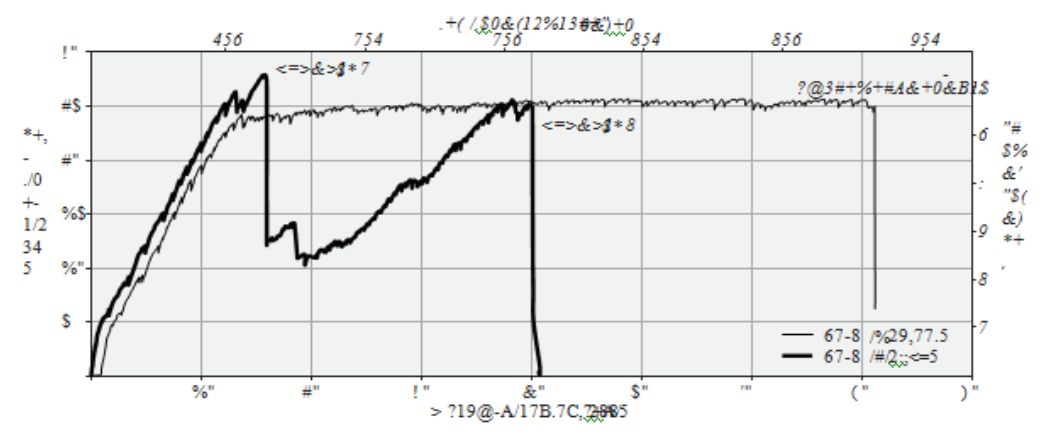

Figure15. Test results, Beam 1 and Beam 2

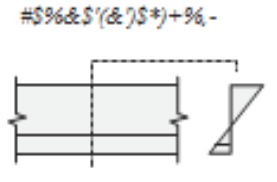

789

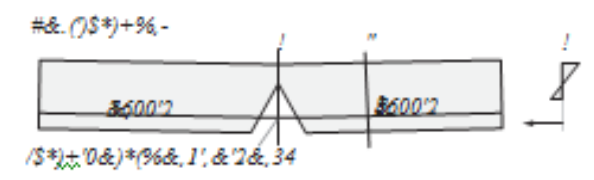

$(\$ * ;+0 \&) *(36 \&, 1 ; \& 2 \&, 3$

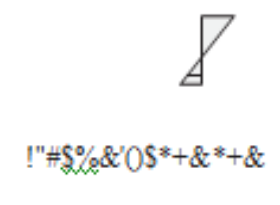

Figure16. Local overstrain in FRP bars 


\section{DISCUSSION}

The testing described above has shown that the splayed bar can satisfactorily be used to provide anchorage in both steel and FRP reinforced fabric formed beams and that the use of a circular helix to confine the concrete is a logical method to prevent premature splitting failures when such an anchorage is used.

In the theoretical bending moment shaped beam, the stress in the curved longitudinal reinforcement may be uniform along its length. In this situation, no bond is required between the bar and the concrete, provided that the end anchorage fails after the bar. The splayed anchorage described above could therefore be used in such a situation and the potential for local overstrains in the bar postcracking would be avoided.

A post-failure assessment of Beam 2 showed that the as-built section was in fact over designed for the chosen loading envelope, and would ideally have been slightly shallower. As tested, Beam 2 was an over reinforced section and thus the observed failure mode was entirely unexpected. However, both tests were successful in demonstrating the efficacy of the splayed bar as an anchorage method.

In design, the provision of ductility is imperative. Where advanced composite reinforcement is used, the section must be over reinforced to facilitate a crushing failure and local overstrains must be avoided by proper assessment of the bond between concrete and FRP. There is a strong argument to be made for keeping both serviceability and ultimate limit state loads within the elastic range, although this may reduce the efficiency of the section.

Compared to a $100 \times 175 \mathrm{~mm}$ (4x6") prismatic beam, the fabric formed beams tested provided a $25 \%$ saving in total concrete volume $\left(0.0261 \mathrm{~m}^{3}\right.$ compared to $\left.0.035 \mathrm{~m}^{3}\right)$. This is slightly less than has been achieved in previous work, although the beams were both overdesigned, failing at nearly twice their design load, suggesting that even greater material use reductions could have been achieved.

\section{THE FUTURE}

\subsection{Reinforcement}

In larger structures, or to satisfy the requirements of reinforced concrete design codes, the provision of shear reinforcement may become a necessity, yet the provision of such reinforcement to a continuously varying cross section has the potential to add significantly to construction costs. The use of a participating fabric formwork system, in which the fabric acts as both formwork and reinforcement, may therefore be advantageous (Figure 17). Advanced composites could allow the designer to simply specify weave directions and densities at various critical points along the length of a beam based on the applied loads. The resulting composite bag could then be filled with concrete to provide an optimised structure that minimises material use.

There are, however, a number of technical hurdles to clear before such a method could be used in general construction. In addition to vandalism and fire protection, an adequate bond between concrete and reinforcement must be provided for the life of the structure and the existing architectural merit of fabric formed concrete structures must be maintained.

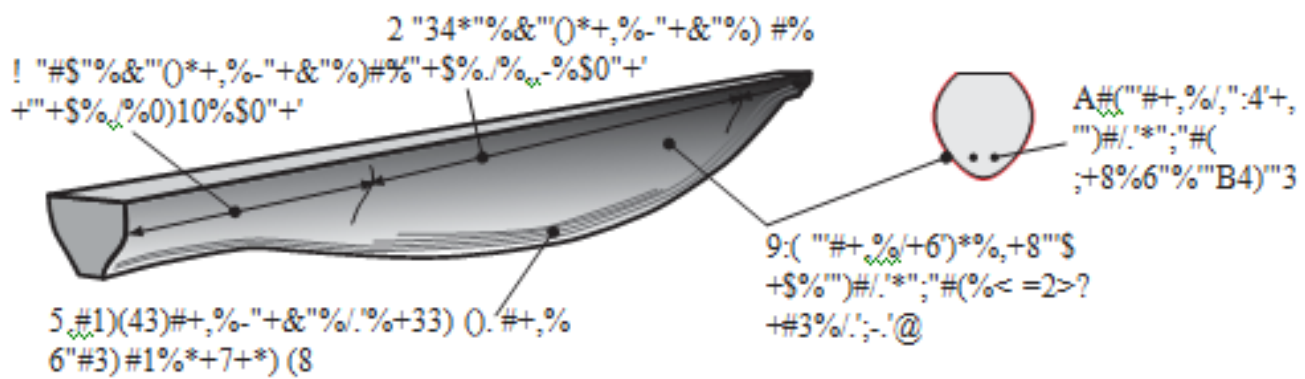

Figure17. Participating fabric formwork

\subsection{Active Reinforcement}

Whilst the use of advanced composite reinforcement holds some advantages for concrete structures, not least in terms of durability, their high working strains limit moment capacity and lead to inferior serviceability characteristics when compared to an equivalent steel reinforced section. Burgoyne ${ }^{20}$ 
argues that advanced composites should instead be used in prestressed structures, where greater moment capacity can be obtained and the full tensile capacity of the tendon utilised. The use of prestressed advanced composite reinforcement in fabric formed structures holds great potential, allowing high strength, durable and architecturally interesting structures to be rapidly and easily cast. In addition, fabric formwork may be used for the construction of uniform strength long span prestressedconcrete beams in which the extreme fibres are at their limiting stress along the entire length of the beam ${ }^{21}$.

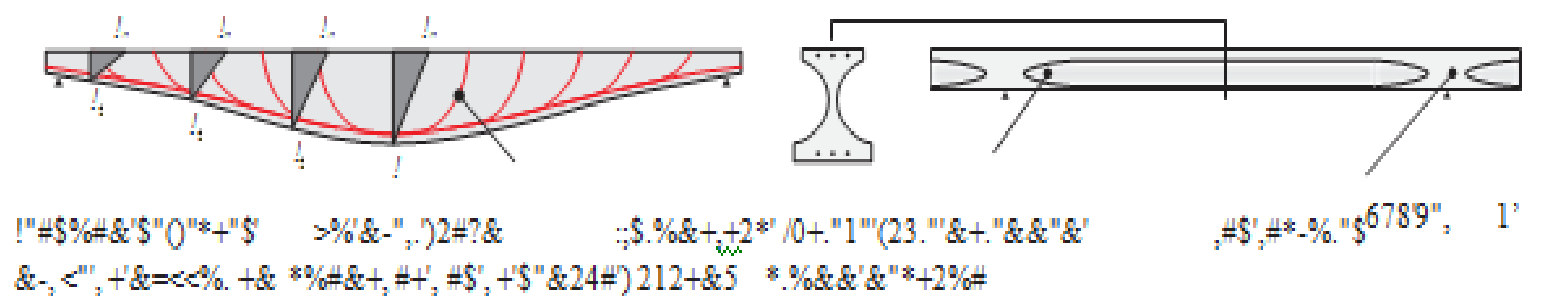

Figure18. Uniform strength, prestressed beam using FRP (l); UHPC beam design ( $r)$

In prestressed structures the use of high and ultra-high performance concrete becomes increasingly advantageous, allowing long span beams to be cast with minimal cross sectional areas and potentially excellent behaviour at the ultimate and serviceability limit states. The use of ultra-high performance concrete in fabric formed concrete structures (Figure 18(r)) is a further part of ongoing research at the University of Bath.

Flexural elements, whilst being simple to design, are fundamentally inefficient and the potential for optimisation is generally limited by serviceability criteria. It is in the design of shell structures that real efficiency and material savings can be found. Using a combination of inexpensive fabric as formwork and lightweight, durable, high strength carbon fibre sheets as reinforcement, medium span shell elements are now a realistic alternative to existing floor and roof systems, as illustrated in Figure 19.

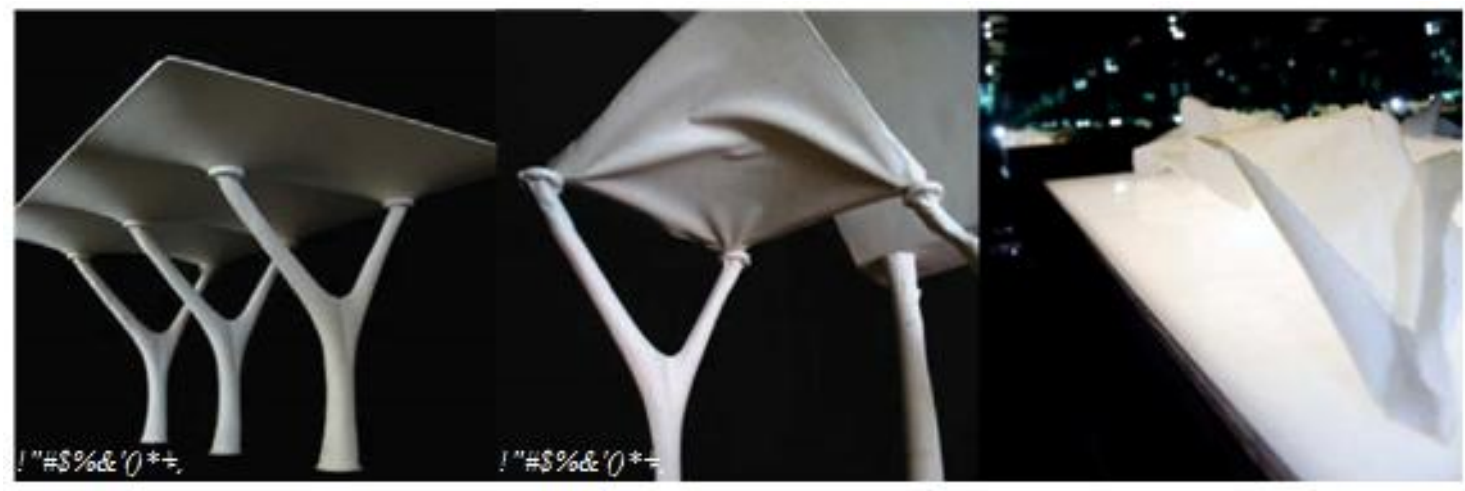

Figure19. Shell structures

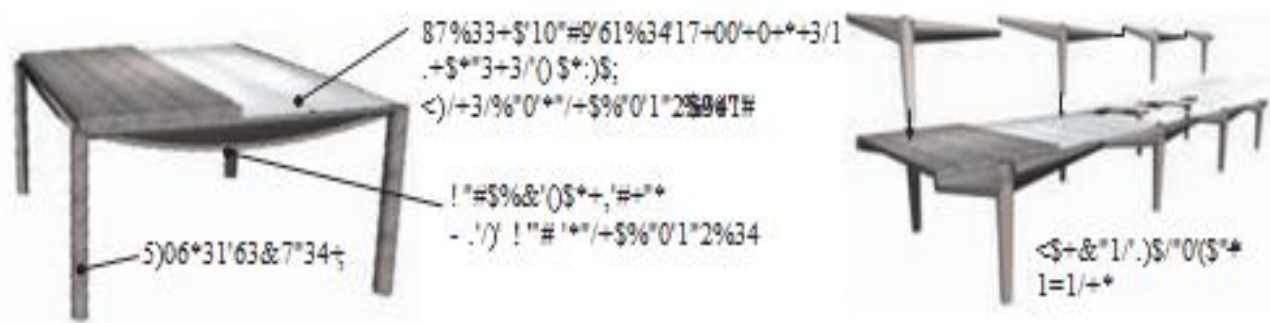

Figure20. Future material savings with fabric formwork

The future application of fabric formwork in the construction industry is illustrated in Figure 20. Here, fabric formed beams are combined with fabric formed shell elements to create materially efficient, optimised structures that bring large embodied energy savings. Early estimates of these savings illustrate the positive changes that fabric formwork could bring to the construction of concrete structures. 


\section{CONCLUSION}

The design of fabric formed concrete structures has, to date, been led primarily by architectural desires. Work at the University of Bath to provide rigorous design methods for these remarkable structures is now well underway. The splayed anchorage method described in this paper overcomes many of the limitations seen in previous tests and can now be used in both steel and advanced composite reinforced structures with confidence, although more detailed and rigorous testing is required to assess the influence of bond between the bar and the concrete before widespread use can be achieved. Fabric formed concrete beams offer significant advantages for designers, including reductions in material use, ease of construction and aesthetic appeal.

Further advantages can be gained through the use of prestressedfibre reinforced polymer reinforcement in fabric formed structures. By prestressing, improvements in both ductility and capacity can be obtained. Additional work is required in the use of flexible carbon fabrics and grids as both external participating reinforcement in beam structures and as internal reinforcement in thinshell elements. A summary of the reinforcement opportunities and challenges for fabric formed concrete beams is provided in Figure 21.

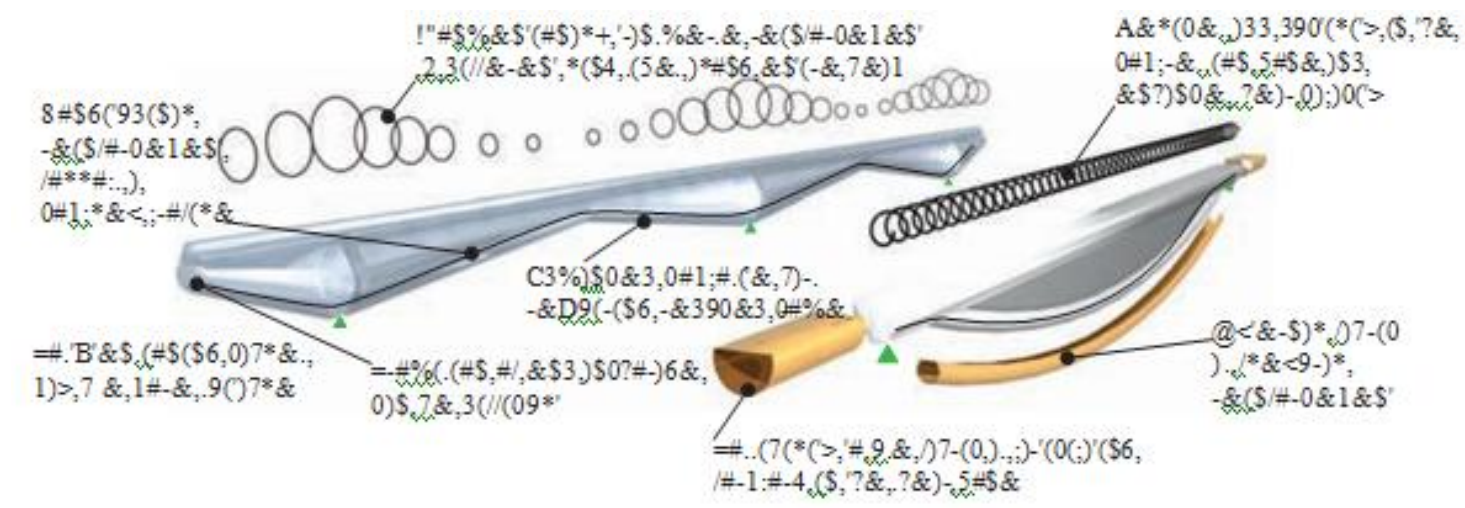

Figure21. Summary of reinforcement methods.

Fabric formwork provides an innovative construction method that has the potential to significantly reduce material use in the construction industry. Design, construction and optimisation routines for these structures are now well established, although further work is required to develop feasible industrial construction methods. The use of new materials, including both advanced composites and high strength fibre reinforced concrete offer additional and exciting opportunities for the field of fabric formwork.

\section{REFERENCES}

[1] Lamberton, B.A., "Fabric forms for concrete", Concrete International, December 1989, pp.58-67.

[2] Orr, J.J., Darby, A P., Ibell, T.J, "Innovative concrete structures using fabric formwork", in SEMC 2010, A.Zingoni, (Editor), Cape Town, South Africa, 2010.

[3] Van Oss, H.G., "Mineral Commodity Summaries: Cement"U.S. Geological Survey Mineral Commodity Summaries, January 2006.

[4] CDIAC, "Fossil-Fuel CO2 emissions", 2005. http://cdiac.esd.ornl.gov/trends/emis /meth_reg.html (accessed March 3 ${ }^{\text {rd }}, 2010$ ).

[5] Bailiss, J., Fabric-formed concrete beams: Design and analysis, MEng Thesis, Department of Architecture and Civil Engineering, Bath, University of Bath, 2006.

[6] Garbett, J., Bone growth analogy for flexibly fomed concrete beams, MEng Thesis, University of Bath, 2008.

[7] Schmitz, R.P., "Fabric formed concrete", in 17th Analysis and Computation Speciality Conference, 2006 Structures Congress, St. Louis, MO, 2006.

[8] Veenendaal, D., Evolutionary optimisation of fabric formed structural elements, Masters Thesis, Department of Civil Engineering and Geosciences, Delft, University of Delft, 2008.

[9] Foster, R., Form finding and analysis of fabric formed concrete beams, MEng Thesis, Architecture and Civil Engineering, Bath, University of Bath, 2010.

[10] Iosilevskii, G., "Shape of a soft container under hydrostatic load", Journal of Applied Mechanics, V.77 No.1, 2010, p 014501. 
[11] BS EN 1992-1-1, Eurocode 2: Design of concrete structures - Part 1-1: General rules and rules for buildings, BSI, London, 2004.

[12] ACI 318, Building code requirements for structural concrete, American Concrete Institute, 2005.

[13] BS 8110-1, Structural use of concrete - Part 1: Code of practice for design and construction, BSI, London, 1997.

[14] Bentz, E.C., Vecchio, F.J., Collins, M.P., "Simplified Modified Compression Field Theory for Calculating Shear Strength of Reinforced Concrete Elements", ACI Structural Journal, V.103 No.4, 2006, p 614-624.

[15] Ibell, T.J., Darby, A.P., Bailiss, J.A., "Fabric formed concrete beams", in ACIC 2007, A.P. Darby, Editor, University of Bath, Bath, 2007.

[16] Ibell, T.J., Darby, A., Denton, S., "Fabric formwork for innovative concrete structures", in FRPRCS-9, Sydney, 2009.

[17] Darby, A.D., Ibell, T.J., Tallis, S., \& Winkle, C., "End Anchorage for Internal FRP reinforcement", in FRPRCS-8, T.C. Triantafillou, Editor, University of Patras, Greece, 2007.

[18] Lees, J.M., Burgoyne, C B, "Experimental Study of Influence of Bond on Flexural Behavior of Concrete Beams Pretensioned with Aramid Fiber Reinforced Plastics", ACI Structural Journal, V.96 No.3, 1999, p 377-386.

[19] Whitehead, P., Ibell, T.J., "Novel shear reinforcement for fibre reinforced polymer reinforced and prestressed concrete", ACI Structural Journal, V.102 No.2, 2005, p 286-294.

[20] Burgoyne, C.J., "Rational Use of Advanced Composites in Concrete", Proc. ICE Structures \& Buildings, V.146, 2001, p 253-262.

[21] Guyon, Y., Prestressed Concrete. London, Contractors Record and Municipal Engineering, 1953.

Citation: Khalil tabatabaei \& farhad tabatabaei "Concrete Fabric New Technology in Concrete Structures”, International Journal of Constructive Research in Civil Engineering, 5(3), pp. 24-34. DOI: http://dx. doi.org/10.20431/2454-8693.0503003

Copyright: (C) 2019 Authors, This is an open-access article distributed under the terms of the Creative Commons Attribution License, which permits unrestricted use, distribution, and reproduction in any medium, provided the original author and source are credited. 